\title{
Socioeconomic status and birth weight: comparison of an area-based measure with the Registrar General's social class
}

\author{
Nick Spencer, Suartini Bambang, Stuart Logan, Leicester Gill
}

\begin{abstract}
Objective-To compare the relation of birth weight with socioeconomic status measured by an area-based measure of material deprivation and by the Registrar General's social class.

Setting-West Midlands Health Region 1991-93.

Study design-Retrospective cohort study.

Method-Birthweight data by enumeration district deciles ranked by Townsend Deprivation Index based on 1991 census data for all live births in the West Midlands Health Region were studied in three consecutive whole year birth cohorts, 1991 to 1993 and by Registrar General's social class in a $10 \%$ sample of live births (within marriage and jointly registered, provided by the Office of National Statistics) in the same region for the same period. Estimated proportions of births $<2500 \mathrm{~g}$ and $<3500 \mathrm{~g}$ "attributable" to social inequalities were compared for both socioeconomic status measures. The proportion of infants in each birthweight group were calculated for both measures. Relative risk ( $95 \%$ confidence intervals) of birth in each birthweight group for lowest versus highest socioeconomic status groups were calculated.
\end{abstract}

Results-The estimated proportions of births < $2500 \mathrm{~g}$ "attributable" to social inequalities were $30 \%$ using the areabased measure and $27 \%$ using the Registrar General's social class. For births $<3500 \mathrm{~g}$, the estimated proportions were $12 \%$ for the area-based measure and $7 \%$ for social class. There was a positive linear relation between the proportion of babies weighing $\geqslant 3500 \mathrm{~g}$ and increasing socioeconomic status measured by either method. Gradients in the opposite direction were noted for the proportion of babies born in the other birth weight groups. Relative risk of birth weight $<3500$ g was $1.30(95 \%$ CIs $1.28,1.32)$ for most versus least deprived decile and 1.17 (95\% CIs $1.10,1.25)$ for social class $V$ versus $I$. For birth weight $<2500 \mathrm{~g}$ the risks were $1.99(95 \%$ CIs $1.85,2.18)$ and $2.04(95 \%$ CIs $1.53,2.73)$ respectively and for birth weight $<1500 \mathrm{~g}, 2.11(95 \%$ CIs $1.73,2.57)$ for most versus least deprived decile (numbers too small for analysis in the Office of National Statistics sample).
Conclusion-A substantial proportion of births $<2500 \mathrm{~g}$ and $<1500 \mathrm{~g}$ are statistically "attributable" to social inequality. The results demonstrate that, using either socioeconomic measure, the likelihood of being born weighing $\geqslant 3500 \mathrm{~g}$, the most advantageous group, is substantially greater in the socially advantaged. Using the area-based measure, an estimated $12 \%$ of births $<3500 \mathrm{~g}$ could be ascribed to social inequalities whereas the same figure using social class was $7 \%$. These findings suggest that this proxy measure of socioeconomic status may be a better discriminator in the study of pregnancy outcomes in this population than classification by occupational social class. Another advantage is its almost universal availability in routine records and its universal population coverage.

(F Epidemiol Community Health 1999;53:495-498)

Low birth weight is a major determinant of perinatal and infant mortality and morbidity. The correlation between low socioeconomic status and low birth weight is well recognised. ${ }^{1}$ Social class, ${ }^{2}$ maternal education, ${ }^{3}$ and income ${ }^{4}$ have been used as individual and householdbased socioeconomic status measures in the study of low birth weight. Annual birth statistics for England and Wales ${ }^{5}$ are the main source of routine birthweight data. Until 1993 they reported Registrar General's social class data for within marriage births. Since then they have reported such data by social class for joint registered births also. Other studies ${ }^{6-8}$ have used area-based socioeconomic status measures. Area-based measures have been reported to underestimate the strength of the associations between socioeconomic status and health outcomes when compared with individual socioeconomic measures. ${ }^{910}$ This paper compares an area-based measure with the Registrar General's social class in studying the relation between socioeconomic status and birthweight.

\section{Methods}

The area-based measure used in the comparison was enumeration districts (ED) ranked into deciles by Townsend Deprivation Index ${ }^{11}$ based on 1991 census data. All live births to women resident within the West Midlands region in the years 1991, 1992, and 1993 were studied. Births for which birth weight and/or postcode of address at birth were not available were excluded from the study as were births to 
Table 1 Comparison of estimated proportion of births $<1500 \mathrm{~g},<2500 \mathrm{~g}$, and <3500 g "attributable" to SES using both SES measures

\begin{tabular}{|c|c|c|c|c|}
\hline \multirow{3}{*}{$\begin{array}{l}\text { Birthweight } \\
\text { group }\end{array}$} & \multicolumn{4}{|c|}{ Proportion of births "attributable" to SES } \\
\hline & \multicolumn{2}{|c|}{ ref group: $E D$ decile $1^{\star}$} & \multicolumn{2}{|c|}{ ref group: RGSCI } \\
\hline & $\%$ & $n / y$ & $\%$ & $n / y$ \\
\hline$<1500 \mathrm{~g}$ & 32 & 168 & ins & at for analysis \\
\hline$<2500 \mathrm{~g}$ & 30 & 1496 & 27 & 1066 \\
\hline$<3500 \mathrm{~g}$ & 12 & 5122 & 7 & 2764 \\
\hline
\end{tabular}

^Townsend Deprivation Index $\leqslant-4.37$.

mothers resident outside the region and births before 24 weeks gestation. Postcodes were converted to ED using Paradox for Windows 5.1 software. $^{12}$

Ranking was by ED decile not population decile and the range of Townsend Deprivation Indices for each decile was as follows: decile 1 $\leqslant 4.37$; decile $2-4.36$ to -3.33 ; decile $3-3.32$ to -2.33 ; decile $4-2.32$ to -1.38 ; decile 5 -1.37 to -0.32 ; decile $6-0.31$ to +0.90 ; decile $7+0.91$ to +2.17 ; decile $8+2.18$ to +3.39 ; decile $9+3.40$ to +4.79 ; decile $10 \geqslant+4.80$.

Data for the same three year period by Registrar General's social class were obtained from the Office of National Statistics. Social class data on all within marriage and jointly registered births are not available as these are collected only on a $10 \%$ sample.

Results obtained with the two measures were compared as follows: estimate of the proportion of births $<2500 \mathrm{~g}$ and $<3500 \mathrm{~g}$ "attributable" to social inequality based on the birthweight distribution in the least deprived decile and social class I; relative risks with $95 \%$ confidence intervals of birth within each birthweight group by most versus least deprived ED decile and social class $\mathrm{V}$ versus I. The $\chi^{2}$ for linear trend for low birthweight $(<2500 \mathrm{~g}$ ), very low birthweight ( $<1500 \mathrm{~g})$ (area-based measure only) and by $500 \mathrm{~g}$ birthweight groups were calculated.

The proportion of births $<2500 \mathrm{~g}$ and $<3500 \mathrm{~g}$ "attributable" to social inequality was estimated by subtracting the number of births $<2500 \mathrm{~g}$ and $<3500 \mathrm{~g}$ obtained when the observed proportions in social class 1 and decile 1 were applied to all births from the observed number of births $<2500 \mathrm{~g}$ and $<3500$ $\mathrm{g}$ and expressing the resulting reduction as a percentage of these observed numbers.
KEY POINTS

- An area-based measure compares favourably with the Registrar General's social class in studying the social gradient in birth weight in routinely collected birth data.

- Area-based measures have the advantage of almost universal availability in routine data and total population coverage.

- Thirty per cent of births $<2500 \mathrm{~g}$ and $32 \%<1500 \mathrm{~g}$ are statistically "attributable" to social inequality.

\section{Results}

There were 208567 live births in the calendar years 1991-93 to mothers with addresses in the region and for whom postcode and birth weight were available. A total of 5620 births were excluded; 5204 because of absence of birthweight data, $416(0.2 \%)$ because of absence of postcode data or postcodes outside the region. The Office of National Statistics data for the three year period relate to 198654 births of which 4573 were excluded from this study as birth weight was not stated. Almost 10000 births were excluded from the Office of National Statistics data as these births were registered to the mother only. The $10 \%$ sample of the remaining 194081 births ( $8 \%$ were excluded as registered only by the mother) included 19359 births for which social class and birthweight data were available.

Twelve per cent of births $<3500 \mathrm{~g}$ were statistically "attributable" to social inequality using the area-based measure compared with $7 \%$ using social class (table 1). For births $<2500 \mathrm{~g}$, the estimated proportions using the area-based measure and social class were similar. Using the area-based measure, the estimated proportion of births $<1500 \mathrm{~g}$ "attributable" to social inequality was $32 \%$. The Office of National Statistics $10 \%$ sample data included too few births in this group for meaningful analysis.

A positive linear relation between the proportion of babies born weighing $\geqslant 3500 \mathrm{~g}$ and increasing socioeconomic status was demonstrated using both measures (tables 2 and 3 ). Analysing by $500 \mathrm{~g}$ birthweight group, gradients in the opposite direction were noted for the proportion of babies born in birthweight groups below 3000 g. For babies born in the

Table 2 Proportion of births in each weight group by enumeration district decile ranked by Townsend Deprivation Index

\begin{tabular}{|c|c|c|c|c|c|c|c|c|}
\hline \multirow[b]{2}{*}{ ED decile } & \multicolumn{8}{|c|}{ Birthweight group $(g)$} \\
\hline & $\begin{array}{l}<2500(l b w) \\
\%(n)\end{array}$ & $\begin{array}{l}<1500 \text { (vlbw) } \\
\%(n)\end{array}$ & $\begin{array}{l}1500-1999 \\
\%(n)\end{array}$ & $\begin{array}{l}2000-2499 \\
\%(n)\end{array}$ & $\begin{array}{l}2500-2999 \\
\%(n)\end{array}$ & $\begin{array}{l}3000-3499 \\
\%(n)\end{array}$ & $\begin{array}{l}3500+ \\
\%(n)\end{array}$ & Live births \\
\hline 1 (TDI $\leqslant-4.36$ ) least deprived & $5.13(888)$ & $0.62(103)$ & $1.01(176)$ & $3.50(609)$ & $13.63(2372)$ & $35.19(6126)$ & $46.05(8016)$ & 17407 \\
\hline 2 (TDI -4.36 to -3.33 ) & $6.02(958)$ & $0.73(116)$ & $1.38(220)$ & $3.91(622)$ & $14.28(2271)$ & $36.16(5749)$ & $43.53(6921)$ & 15899 \\
\hline 3 (TDI -3.32 to -2.33 ) & $5.66(828)$ & $0.71(104)$ & $1.16(170)$ & $3.79(554)$ & $14.66(2142)$ & $35.26(5151)$ & $44.41(6488)$ & 14609 \\
\hline 4 (TDI -2.32 to -1.38 ) & $5.90(966)$ & $0.84(138)$ & $1.20(196)$ & $3.86(632)$ & $14.49(2376)$ & $35.86(5879)$ & $43.75(7172)$ & 16393 \\
\hline 5 (TDI -1.37 to -0.32 ) & $6.74(1168)$ & $0.66(114)$ & $1.41(245)$ & $4.34(752)$ & $15.44(2675)$ & $35.69(6182)$ & $42.15(7297)$ & 17322 \\
\hline 6 (TDI -0.31 to +0.90$)$ & $6.50(1234)$ & $0.66(125)$ & $1.27(242)$ & $4.32(820)$ & $16.46(3124)$ & $36.35(6901)$ & $40.69(7725)$ & 18984 \\
\hline 7 (TDI 0.91 to 2.17 ) & $7.14(1529)$ & $0.60(129)$ & $1.40(301)$ & $4.82(1033)$ & $17.67(3787)$ & $36.01(7716)$ & $39.19(8397)$ & 21429 \\
\hline 8 (TDI 2.18 to 3.39 ) & $8.19(1885)$ & $0.86(199)$ & $1.76(406)$ & $5.34(1229)$ & $18.36(4226)$ & $37.24(8570)$ & $36.21(8333)$ & 23014 \\
\hline 9 (TDI 3.40 to 4.79 ) & $8.41(2267)$ & $0.82(222)$ & $1.63(440)$ & $5.63(1518)$ & $19.95(5380)$ & $37.22(10039$ & $34.42(9283)$ & 26969 \\
\hline 10 (TDI 4.80 to 8.76 ) most deprived & $9.79(3578)$ & $0.90(329)$ & $1.94(708)$ & $6.57(2401)$ & $22.39(8180)$ & $38.05(13902$ & $29.78(10880)$ & 36540 \\
\hline$\chi^{2}$ for linear trend & 616.7 & 67.6 & 97.0 & 423.6 & 1168.9 & 91.2 & 2317.0 & \\
\hline $\mathrm{p}$ values & $<0.000$ & $<0.000$ & $<0.000$ & $<0.000$ & $<0.000$ & $<0.000$ & $<0.000$ & \\
\hline
\end{tabular}


Table 3 Proportion of infants in each birthweight group * by Registrar General's social class

\begin{tabular}{llllllll}
\hline \multicolumn{7}{l}{ Birthweight group } \\
\cline { 2 - 8 } RG's social class & $\begin{array}{l}\text { <2500 } \\
\%(n)\end{array}$ & $\begin{array}{l}1500-1999 g \\
\%(n)\end{array}$ & $\begin{array}{l}2000-2499 g \\
\%(n)\end{array}$ & $\begin{array}{l}2500-2999 g \\
\%(n)\end{array}$ & $\begin{array}{l}3000-3499 g \\
\%(n)\end{array}$ & $\begin{array}{l}3500+g \\
\%(n)\end{array}$ & $\begin{array}{l}\text { Total live } \\
\text { births }\end{array}$ \\
\hline I & $5.51(63)$ & $1.40(16)$ & $3.50(40)$ & $14.70(168)$ & $36.66(419)$ & $43.13(493)$ & 1143 \\
II & $6.39(263)$ & $1.04(43)$ & $4.47(184)$ & $16.00(658)$ & $35.11(1446)$ & $42.53(1752)$ & 4119 \\
IIIn & $6.49(111)$ & $1.05(18)$ & $4.50(77)$ & $14.33(245)$ & $37.31(638)$ & $41.87(716)$ & 1710 \\
IIIm & $7.59(565)$ & $1.24(92)$ & $5.21(388)$ & $17.28(1287)$ & $37.26(2775)$ & $37.87(2820)$ & 7447 \\
IV & $7.39(224)$ & $1.58(48)$ & $4.65(141)$ & $18.77(569)$ & $37.34(1132)$ & $36.51(1107)$ & 3032 \\
V & $11.28(128)$ & $2.64(30)$ & $7.56(86)$ & $21.37(243)$ & $33.94(386)$ & $33.42(380)$ & 1137 \\
Other & $10.51(81)$ & $2.33(18)$ & $6.87(53)$ & $21.27(164)$ & $36.45(281)$ & $38.81(245)$ & 771 \\
$\chi^{2}$ for linear trend & 37.01 & 14.15 & 19.41 & 38.12 & 0.440 & 75.86 & \\
p value & $<0.000$ & $<0.000$ & $<0.000$ & $<0.000$ & $0.512(\mathrm{NS})$ & $<0.000$ & \\
\hline
\end{tabular}

ॠNumber of $<1500 \mathrm{~g}$ births too small for meaningful analysis.

Table 4 Relative risks lowest compared with highest social group for area-based measure and RGSC by birthweight group

Relative risks (95\% confidence intervals)

Area-based measure $\quad$ RGSC

(ref group: ED decile 1) (ref group: RGSCI)

Birthweight group

$\begin{array}{lll}<3500 \mathrm{~g} & 1.30(1.28,1.32) & 1.17(1.10,1.25) \\ <2500 \mathrm{~g} & 1.99(1.85,2.18) & 2.04(1.53,2.73) \\ <1500 \mathrm{~g} & 2.11(1.73,2.57) & \star\end{array}$

^Numbers too small for meaningful analysis.

birthweight group 3000-3499 g, a statistically significant linear trend with decreasing socioeconomic status $(p<0.000)$ was found using the area-based measure but no relation was found using social class.

The relative risk of birth weight $<3500 \mathrm{~g}$ in the lowest versus highest socioeconomic status group was significantly greater for the areabased measure compared with social class (table 4). Relative risks of birth in the remaining birthweight groups were similar.

\section{Discussion}

Interpretation of the results of this study should take account of limitations in the study design. Data obtained from the West Midlands region related to all births within the three year study period. Birth weight and postcode could be extracted from these data. Data for births in the same region for the same period classified by Registrar General's social class could be obtained only from the Office of National Statistics. Social class classification is only available on a $10 \%$ sample of within married and jointly registered births. Births registered by the mother only are excluded from these data. Thus, the results based on the area-based socioeconomic status measure are derived from the total birth population and compared with results from a $10 \%$ sample of a selected group within the same population.

The Registrar General's social class divides the population into seven groups whereas the area-based measure is divided into deciles. A greater differentiation between the extremes of socioeconomic status would be expected for the area-based measure compared with social class simply as a result of the higher number of sub-divisions.

However, these limitations arise as a result of reliance in Office of National Statistics data on the Registrar General's social class and exclusion of the most deprived social group from available birth data and are limitations that affect the interpretation of social gradients using these data. It is part of the purpose of this paper to explore whether an area-based socioeconomic status measure, based on postcode that is available on all births and covers the whole population, could provide a simple universally applicable alternative to Registrar General's social class in the analysis of social gradients in routine birth data.

This study confirms that an area-based socioeconomic status measure achieves almost universal coverage of the birth population and permits classification into relatively homogeneous socioeconomic groupings. Only $0.2 \%$ of births could not be assigned to a social group using the area-based measure compared with $8 \%$ of births registered only by the mother that were automatically excluded from the Registrar General's social class classification. Using the Registrar General's classification, a further $4.3 \%$ of births, for which data were available, were difficult to classify and fell into the "Other" group. It is difficult to interpret data from this group as it consists of a heterogeneous mix including, among others, students and members of the armed forces.

The findings show that an area-based socioeconomic status measure, using the Townsend Deprivation Index derived from census data at ED level, demonstrate a similar social gradient in birth weight to social class based on the occupation of the head of the household. The area-based measure demonstrates a stronger association with birth weight than social class particularly in relation to the two important birthweight groups-<3500 g and $<1500 \mathrm{~g}$. Both socioeconomic status measures show that the likelihood of birthweight $\geqslant 3500 \mathrm{~g}$ is substantially greater in the socially advantaged. However, using the area-based measure, $12 \%$ of births $<3500 \mathrm{~g}$ could be statistically "attributed" to social inequality compared with $7 \%$ using the Registrar General's social class suggesting that, in this population, social class may be underestimating the social gradient associated with birth in the weight group $(\geqslant 3500 \mathrm{~g})$ that is known to confer the greatest advantage in the first year of life ${ }^{13}$ and possibly into adulthood. ${ }^{14}$

The $10 \%$ Office of National Statistics sample limits comparison of the social gradient identified using the area-based measure with the social class gradient for births $<1500 \mathrm{~g}$. Despite a tendency to plateau in the middle 
deciles, the area-based measure shows a clear, statistically significant social gradient for this birthweight group that is associated with the worst perinatal outcomes. These findings tend to contradict the conclusions reached in a recent Office of National Statistics publication ${ }^{1}$ that "there is little difference across the social classes for the smallest babies, weighing under $1.5 \mathrm{kgs}$ except that the rate for social class $\mathrm{V}$ is higher than for the other classes" (chapter 7, page 87).

The stronger relations between socioeconomic status and birth weight shown with the area-based measure in this study may be explained, in part, by the use of 10 divisions compared with seven for social class. However, the much larger population in the most deprived deciles, resulting from the division into ED rather than population deciles, is likely to have resulted in an apparent reduction in birthweight differences whereas the social class distribution is likely to have exaggerated differences. It is probable that the stronger associations are also related to the inclusion of mother only registered births in the area-based data and their exclusion from the Office of National Statistics data as these births are at increased risk of low birth weight and preterm delivery. The more homogeneous social groupings represented by the area-based measure compared with social class may also partly explain these findings. The stronger association of individual compared with area-based measures with reproductive outcomes shown in Kreiger's study ${ }^{9}$ may be related to greater precision in the individual measures than is given by the Registrar General's social class and less precision in the area-based measures. The use of smaller, more socially homogeneous areas in this study is consistent with suggested methods for the reduction of the potential effects of the "ecological fallacy". ${ }^{15} 16$ The Registrar General's social class has been criticised as a socioeconomic status measure in the study of perinatal and early childhood health outcomes. ${ }^{17}$ This study is further confirmation that social class, especially when combined with a policy of excluding mother only registered births, is likely to underestimate the extent of social difference in birth outcomes and may need to be supplemented by more sensitive indicators of deprivation in public health research and practice. ${ }^{18}$
This study demonstrates that a socioeconomic status measure, based on small, relatively homogeneous areas, compares well with occupational social class in studying the social patterning of birth weight in routinely collected health service data. The almost universal availability of postcodes in routine data sets provides a simple alternative measure that encompasses the whole birth population. The use of area-based measures in national, regional, and local perinatal data sets should be considered.

Funding: Ms Bambang was funded by the World Bank. Conflicts of interest: none.

1 Drever F, Whitehead M. Health inequalities. Series DS no15. London: Office of National Statistics, The Stationery Office, 1997.

2 Fedrick J, Adelstein P. Factors associated with low birth weight of infants delivered at term. Br $\mathcal{F}$ Obstet Gynaecol 1978;85:1-7.

3 Read AW, Stanley FJ. Small-for-gestational-age term birth: the contribution of socio-economic, behavioural and biological factors to recurrence. Paediatr Perinat Epidemiol 1993;7:177-94.

4 Starfield B, Shapiro S, Weiss J, et al. Race, family income and low birthweight. Am f Epidemiol 1991;134:1167-74.

5 Office of National Statistics (formerly OPCS). Perinatal and infant mortality: social and biological factors. DH3 series. London: HMSO, annual.

6 Reading R, Openshaw S, Jarvis SN. Measuring child health inequalities using aggregations of enumeration districts. $\mathcal{F}$ inequalities using aggregations of
Public Health Med 1990;12:160-7.

Public Health Med 1990;12:160-7.
7 Wilcox MA, Smith SJ, Johnson IR, et al. The effect of social deprivation on birthweight, excluding physiological and pathological effects. Br f Obstet Gynaecol 1995;102:918-24.

8 Elmen H, Hoglund D, Karlberg P, et al. Birth weight for gestational age as a health indicator: birth weight and mortality measures at a local level. European fournal of Public Health 1996;6:137-41.

9 Krieger N. Overcoming the absence of socio-economic data in medical records: validation and application of censusbased methodology. Am F Public Health 1992;86:703-10.

10 Sloggett A, Joshi H. Higher mortality in deprived areas: community or personal disadvantage? BMF 1994;309: 1470-4.

11 Townsend P, Phillimore P, Beattie A. Health and deprivation: inequality and the North. Beckenham: Croom Helm, 1988.

12 MIDAS PC/ED Conversion Directory. Manchester: Manchester Information Datasets and Associated Services, University of Manchester, 1995.

13 Platt MJ, Pharaoh POD. Child health statistical review, 1996. Arch Dis Child 1996;75:527-33.

14 Barker DJP, Osmond C, Simmonds SJ, et al. The relation of small head circumference and thinness at birth to death from cardiovascular disease in adult life. BMF 193;306: $422-6$.

15 Morgenstern $\mathrm{H}$. Uses of ecologic analysis in epidemiologic research. Am f Public Health 1982;72:1336-44.

16 Reading R, Openshaw S, Jarvis SN. Are multidimensional social classifications of areas useful in UK health service reciarch? f Epidemiol Community Health 1994;48:192-200.

17 Cooper J, Botting B. Analysing fertility and infant mortality booper J, Botting B. Analysing fertility and infant mortality
by mother's social class as defined by occupation. Popul by mother's social clas
Trends 1992;70:15-21.

18 Bartley M, Power C, Blane D, et al. Birth weight and later socioeconomic disadvantage: evidence from the 1958 British cohort study. BMF 1994;309:1475-8. 